Revista Iberoamericana, Vol. LXXVI, Núm. 231, Abril-Junio 2010, 495-503

\title{
SIGUIENDO LAS PISTAS DE LA NOVELA NEGRA CON MEMPO GIARDINELLI
}

\author{
POR \\ WiLLIAM John Nichols \\ Georgia State University
}

Mempo Giardinelli, un escritor y pensador de primera categoría, ofrece al lector un espacio textual -sea éste narrativo, periodístico, o ensayístico- en el cual se explora la encrucijada de la política, la cultura y la conciencia social. Su obra literaria se ofrece como una conversación, o diálogo si se quiere, con sus lectores en la cual los invita a explorar, cuestionar y cruzar una serie de fronteras: tales como las fronteras entre la ficción y la realidad, la ética y la estética, o la memoria y el deseo. Desde sus ensayos sobre el género negro a la crónica de su viaje a la Patagonia, estas exploraciones son internas -radiografías de la conciencia individual, de los códigos genéricos y de su propio propósito como escritor. A la vez, su escritura extiende una mirada externa para ofrecer la literatura como un arma contra la represión, la subyugación, la pobreza, la humillación y la resignación. En la escritura, entonces, Mempo Giardinelli busca la reivindicación de utopías tanto sociales como literarias: donde se puede encontrar y propagar la solidaridad, la honradez e, incluso, la resistencia y la revolución. Con su novela Luna caliente (1983), Mempo incursiona en el territorio del género negro para ofrecer una crónica, irónicamente alegórica del ambiente sofocante durante el llamado "Proceso de Reorganización Nacional” que duró de 1976 a 1983 en Argentina. Este género le permite explorar la relación entre la ética y la literatura, y vuelve a la novela negra con Qué solos quedan los muertos (1985), El décimo infierno (1999) y Cuestiones interiores (2003). Su libro titulado simplemente El género negro. Ensayo sobre la novela policial (publicado en 1984 y revisado en 1996) se ha establecido como uno de los estudios fundamentales sobre la novela negra; allí reconoce que noir adquiere tanta influencia en América Latina porque es un género que trata los temas y valores que están más amenazados en la cultura y la política latinoamericanas: la verdad y la justicia. Como otros de los ensayos de este número dedicado a la novela negra han demostrado, Mempo encuentra en la novela negra un género híbrido que mira hacia dentro para cuestionar las fronteras estéticas que lo delimitan, a la vez 
que se dirige hacia el mundo externo con una sensibilidad desconfiada en busca del honor y la ética. Aquí se presenta una entrevista con Mempo en la cual explora las repercusiones estéticas, culturales, ideológicas, sociales y políticas del género negro en el mundo latino.

William John Nichols: ¿Cómo es esa teoría que tú tienes sobre los orígenes del género negro en vinculación con la literatura del far-west norteamericano?

Mempo Giardinelli: -No es una "teoría" sino una idea, que desarrollo en mi libro El género negro. Allí digo que cualquiera que haya sido lector de la literatura del Oeste norteamericano del siglo xIx coincidirá conmigo en que hay muchos elementos comunes, y un mismo estilo narrativo, en el paso del ambiente rural a la ciudad. No pocos de los autores de policiales que hoy estimamos fueron, anteriormente, exitosos autores de novelas y relatos del Oeste. Es el caso de Frank Gruber, por ejemplo.

Fereydoun Hoveyda establece, en su conocida Historia de la novela policiaca, que entre los antecedentes de nuestro género hubo incluso manuscritos chinos, y menciona como antecedentes a los trabajos del inglés William Godwin y del francés Eugene Vidocq. Sólo después llega Edgar Allan Poe, a quien se considera padre del género. Lo cual está muy bien, pero hubo muchos más: Eugenio Sue (1804-1857), Emile Gaboriau (1832-1873) y William Wilkie Collins (1824-1889), por lo menos.

Lo que yo sostengo en mi libro es que desde aquellas obras iniciales hasta la moderna novela negra, hubo un largo camino en el que esta literatura recibió préstamos de otros géneros que podrían ser considerados sus "primos hermanos", y que contribuyeron a determinar sus características. Entre ellas, la llamada literatura gótica o de horror(Mary Wollstonecraft Shelley, Nathanael Hawthorne, Bram Stoker, Howard Phillip Lovecraft), la de aventuras (Herman Melville, Joseph Conrad, Jack London, John Dos Passos) y la casi siempre olvidada literatura del Oeste norteamericano (Francis Brett Harte, Ambrose Bierce y Zane Grey, entre otros).

De todos ellos tomó la moderna literatura negra los elementos que hoy la caracterizan: el suspenso, el miedo que provoca ansiedad en el lector, el ritmo narrativo, la intensidad de la acción, la violencia, el heroísmo individual. Con esas materias primas, Hammett primero, Chandler después, y un montón de autores no del todo reconocidos más tarde, sentaron las bases de la novela negra: la lucha del "bien” contra el "mal”, la intriga argumental y, siempre, la ambición, el poder, la gloria y el dinero como elementos capaces de torcer el destino de los seres humanos. Todo lo cual también fue esencial a la literatura del far-west.

WJN: ¿Qúe otros géneros asocias con el desarrollo del género negro (bien como una asimilación de otro género o bien como una reacción en contra de ello)?

\footnotetext{
Revista Iberoamericana, Vol. LXXVI, Núm. 231, Abril-Junio 2010, 495-503 ISSN 0034-9631 (Impreso) ISSN 2154-4794 (Electrónico)
} 
MG:-El género negro se toca, en sus mejores expresiones, con la mejor literatura universal. Esto es algo que ya Chandler estableció hace décadas, y yo creo que es verdad, pero, subrayo, sólo en sus mejores expresiones. El largo adiós, por ejemplo, es una gran novela. No es una gran novela “policial”, sino una gran novela. Y 1280 almas de Jim Thompson, o algunas de las mejores de Horace McCoy, James Cain, José Giovanni o Chester Himes, también.

Lo que intento decir, entonces, es que no tenemos que seguir validando este género a partir de contactos o asociaciones con otros géneros. En todo caso, son algunos géneros menores los que han venido a servirse del mejor policial y bueno, el resultado es una variopinta y extensísima colección de malas novelas de géneros menores: el de espionaje, el dizque tecnológico, el thriller ecologista, el electrónico, el de terror hollywoodense y etc., etc., etc.

WJN: En cuestiones terminológicas, ¿qué abarca el género negro? ¿Qué se incluye bajo esa etiqueta y qué se excluye?

MG: -En primer lugar, yo no creo que el género negro sea una "etiqueta". Pienso que es un género literario que en el siglo xx ha dado muchas obras que son parte de lo mejor de la narrativa universal. Y lo que abarca es lo mismo que contiene la buena literatura: una mirada y una indagación -inteligente, profunda y sin concesiones- sobre lo que llamamos "la condición humana".

En 1958 y en Francia, Thomas Narcejac escribió un trabajo fundamental en el que analizó el progreso de esta novelística a través del tiempo: cómo de lo “maravilloso cándido" (novela gótica) se pasó a lo "maravilloso lógico" (policial clásico, racional y positivo), que es lo que a su vez transformó a la novela de aventuras en novela policial. De hecho, Narcejac en cierto modo anticipó lo que posteriormente se llamó "real maravilloso": "El mundo que nos rodea no es sino una mera apariencia y la solución del misterio no depende exclusivamente de la lógica humana”. De ahí que la novela negra moderna supone "a la vez una explicación lógica y una explicación metalógica; o, en otros términos, ofrece una dimensión racional y otra dimensión fantástica”. En mi libro sostengo que el trabajo de Narcejac es francamente revolucionario y anticipatorio. Porque antes de que autores como Carlos Fuentes, Gabriel García Márquez o Julio Cortázar admitieran las influencias recibidas de la literatura norteamericana en general, y la policíaca en particular, él ya advertía que lo policiaco, desde Hammett, "se mantiene entre lo real (novela naturalista) y lo imaginario puro (ciencia ficción)”. De donde podemos reafirmar, una vez más, que la influencia de la novela policial en la narrativa latinoamericana contemporánea es insoslayable.

WJN: ¿Cuál es la distinción entre lo policíaco y lo negro? ¿Existe alguna conexión entre estos términos?

MG:-Originalmente parecía que el policial se ocupaba solamente de narrar el proceso de descubrir y atrapar al malhechor, ladrón o asesino. Pero con el tiempo, y

Revista Iberoamericana, Vol. LXXVI, Núm. 231, Abril-Junio 2010, 495-503
ISSN 2154-4794 (Electrónico) 
gracias a muchas buenas novelas, se desarrolló una mucho mayor preocupación por atrapar al lector antes que al malhechor. Y esto no es un mero juego de palabras. Con la evolución, cambiaron los sentidos del texto, los escenarios, las responsabilidades, la visión étnica y racial, y lógicamente fueron cambiando los públicos lectores.

El cambio fue notable a partir de Hammett y sus seguidores, y en mi opinión una diferencia interesante es que se fueron multiplicando los puntos de vista. En mi libro El género negro, precisamente, desarrollo la evolución de los puntos de vista del criminal y de la víctima, que son dos expresiones modernas.

Aunque también quiero decir que hoy en día me parece que hay un enorme riesgo de repetición y vaciamiento. Así como la novela policial clásica acabó repitiéndose hasta el hartazgo, el nuevo relato negro puede estar cayendo en similar agotamiento. En mi opinión, el riesgo está a la vista. Y pienso, entonces, que el problema de la fatiga de este género es algo que merecería más atención. Yo todavía no veo cómo se va a resolver, pero sé que el riesgo existe. Quizás ésta sea la gran limitación del género negro, como lo fue del policial clásico.

WJN: En tu libro, El género negro, hablas sobre las transformaciones del género a manos de autores latinoamericanos. ¿Puedes hacer algunas precisiones al respecto?

MG: -Bueno, sí, a mí me parece que la novela policíaca latinoamericana se ha distanciado bastante positivamente de la anglosajona. No creo que haya habido ninguna revolución, pero sí se pueden observar algunas peculiaridades muy interesantes. Sobre todo porque la latinoamericana se vincula con lo social, o sea con la vida de nuestros pueblos, mientras que la anglosajona ha estado siempre vinculada casi exclusivamente a lo individual, y/o a subrayar el heroísmo personal. En cambio, entre nosotros el heroísmo personal es mucho menos apreciado y esto ha significado un cambio fundamental para el género. Como sostengo en mi libro, el género negro norteamericano, y en cierto modo también el europeo, se basan política y filosóficamente en la confianza y seguridad que brindan sus instituciones, mientras en América Latina eso es impensable porque aquí las instituciones del Estado son vistas como enemigas ganadas por la corrupción o el negocio de la política, y no suele haber ninguna confianza en ellas.

WJN: ¿Cuáles son, a tu criterio, las implicaciones ideológicas del género?

MG:-Las que acabo de mencionar, desde luego. Y aquí quiero subrayar que el género negro norteamericano, y en cierto modo también el europeo, se basa política y filosóficamente en la confianza en el Estado y en la capacidad regenerativa de sus instituciones. Por eso el Detective funciona como auxiliar de la Policía y de la Justicia. Lo cual en América Latina es impensable, porque nosotros sabemos que esas instituciones del Estado han sido ganadas por la corrupción o el negocio de la política, y no hay ninguna confianza en ellas. Y otra implicancia ideológica es que

Revista Iberoamericana, Vol. LXXVI, Núm. 231, Abril-Junio 2010, 495-503
ISSN 2154-4794 (Electrónico) 
para los autores de los Estados Unidos éste es un género de entretenimiento con el que se puede ganar dinero, mientras que para nosotros es un género literario capaz de denunciar vigorosamente las injusticias y las situaciones más escandalosas.

Cuando yo empecé a trabajar en narrativa policial, creo que tuve las mismas motivaciones que tuvimos todos los que nos sumergimos en esto: la lectura de los clásicos del género en medio de las crisis políticas latinoamericanas. Al menos en los años '70, y en la Argentina, muchos de los que entonces éramos muchachos compartíamos la misma pasión literaria y nos fascinaba todo aquello que aludía a la realidad desde perspectivas contrastantes y sobre todo críticas. Yo llegué a Buenos Aires en 1969 y uno de mis primeros amigos allí fue Osvaldo Soriano, con quien trabajamos en una revista que se llamó Semana Gráfica. Y todo el tiempo intercambiábamos libros, descubríamos autores y coleccionábamos la famosa serie "El séptimo círculo” creada por Borges y Bioy Casares para la editorial Emecé. Supongo que la época misma, el clima contestatario, nuestra juventud y la pasión literarias hicieron el resto. La combinación era como el gimlet en El largo adiós de Chandler: irresistible.

WJN: Por lo general, la novela negra se ve poblada por un sinfín de personajes marginados que viven al margen de una sociedad moderna donde sufren las inconsistencias y las contradicciones de un sistema supuestamente democrático que aboga valores como justicia, verdad, razón y lógica. ¿En la novela negra latinoamericana, ¿quiénes son los marginados? ¿Qué comentarios se encuentran en estas novelas sobre los llamados valores modernos Latinoamérica?

MG:-Es difícil, y sería demasiado largo, pretender establecer con exactitud el aporte ideológico de la literatura latinoamericana al género policial. Pero sí sé que en cierto modo los que vivimos en Latinoamérica somos todos, en esencia, marginados. Y todos estamos jodidos, de manera que en estas novelas nos encontramos todos, desde hace años, y me parece que esa ha sido la razón de su enorme popularidad. Y de ahí que este género es determinante para comprender la literatura latinoamericana contemporánea.

Pero además sucede que hoy yo tengo una visión mucho menos solemne de la literatura, y por ende del género negro, y entonces la verdad es que ya no me importa tanto si es más o menos ideológica, ni tampoco si aporta mucho o poco, ni qué es lo que aporta. Hoy lo que me interesa destacar es que sigue siendo uno de los géneros literarios más placenteros y el que mejor nos permite cuestionar siempre todo, y desde los libros fastidiar a los poderosos. No es poca cosa.

WJN: A pesar de la compleja diversidad cultural de Latinoamérica, el género negro es una constante que se encuentra en el paisaje literario desde Argentina hasta río Bravo y abarcando países caribeños, e incluso podríamos incorporar autores chicanos de los Estados Unidos y la proliferación del género en la Península Ibérica.

Revista Iberoamericana, Vol. LXXVI, Núm. 231, Abril-Junio 2010, 495-503
ISSN 2154-4794 (Electrónico) 
En su opinión, ¿cuáles son los factores comunes en el ámbito social, político, económico, etc. que fomentan la producción de este género?

MG:-Como acabo de mencionar, la producción latinoamericana de este género se nutre de la desdicha de nuestros pueblos. Pero no es una mirada de lamentación sobre nuestras desdichas, sino una mirada muchas veces aguda y cuestionadora, y eso también la enaltece. Por ejemplo, entre nosotros hay mucha pobreza, y eso las novelas negras lo reconocen, pero no admiten la humillación. Otro ejemplo: en las novelas negras latinoamericanas es muy importante la corrupción, pero vista desde una posición anti imperialista: o sea que la corrupción comprende a nuestros corruptos, desde luego, pero también a quienes los corrompen a ellos, que son sus patrones de fuera. Lo que estoy diciendo, por lo tanto, es que hay una nueva y diferente legalidad narrativa.

WJN: En los Estados Unidos, el género negro nace en un momento de crisis durante los años 20, en la era de la prohibición, gangsterismo y el crac financiero, ¿Se puede destacar algún momento histórico o cultural que marca el principio y el impulso de la proliferación del género negro en Latinoamérica?

MG:-Sí, claro, la proliferación del género va de la mano del proceso de dictaduras y anticomunismo infantil que provocaron los Estados Unidos en América Latina, y producto del cual fueron tantas dictaduras feroces. Claramente, esto sucedió a partir de los años 70. Hasta entonces, el género policial en Latinoamérica era bastante ingenuo y ceñido a narrar la cacería del malhechor a la manera europea. O sea que aquí también es el proceso de crisis el que desarrolla al género negro.

WJN: En los Estados Unidos, el género negro nació en las páginas ásperas de las famosas revistas pulp, como Black Mask, Dime Detective Magazine, y Detective Story que se imprimían en papel de baja calidad y se vendían por muy poco dinero. El marketing y la producción material de estas revistas se dirigían a la clase obrera norteamericana en la época de las guerras y complementaba en cierto sentido la postura ideológica de escritores como Dashiell Hammett, Raymond Chandler y Carroll John Daly. ¿ Se percibe algo similar en la producción material de las novelas del género negro en Latinoamérica donde el texto físico y su precio facilitan el consumo de ello por las clases obreras? ¿ $\mathrm{O}$ son textos que se dirigen, tanto en su producción material como estética, a una clase media acomodada? ¿Cuáles serían las implicaciones de esto?

MG: -Bueno, la verdad es que no estoy de acuerdo con los presupuestos de esta pregunta. Porque si bien es cierto que en los Estados Unidos el género nació en aquellas revistas, me parece evidente que jamás hubo una postura ideológica común en Hammett y Chandler: Hammett era un hombre de izquierda y Chandler era de derecha. Y casi todos los mejores narradores del género, originalmente, no tenían una posición política definida. Pero además, yo no creo que jamás ninguna

\footnotetext{
Revista Iberoamericana, Vol. LXXVI, Núm. 231, Abril-Junio 2010, 495-503 ISSN 0034-9631 (Impreso) ISSN 2154-4794 (Electrónico)
} 
literatura se haya dirigido a la clase obrera, salvo el estalinismo, que precisamente dio una literatura olvidable. En todo caso, la relación entre texto físico (o sea papel barato) y precio económico fue siempre una característica de todo género popular, no sólo del policial. Y así seguirá siendo en cualquier país del mundo.

WJN: Desde su nacimiento muchos han considerado el género negro y la novela policíaca en general como una escritura escapista y poco seria. ¿Piensa que el género negro en Latinoamérica rompe la barrera, a veces rígida, entre lo que se considera alta cultura y lo que es cultura popular?

MG:-Bueno, ya se sabe que los prejuicios mueven al mundo, y así andamos... Y los que afectan al género negro y la novela policíaca en general siguen siendo muchos y muy grandes. Todavía hoy, para mucha gente, resulta inexplicable la fascinación que esta literatura ejerce sobre millones de personas. Sin embargo, a pesar de tan masiva aceptación, esta literatura todavía es considerada "menor". Como si lo policíaco estuviese condenado, más allá de la masividad de sus cultores, a seguir siendo un "subgénero", una especie de hijo ilegítimo de la literatura "seria".

Ese menosprecio no ha impedido que de todos modos se haya impuesto universalmente. La novela negra impregna hoy en día nuestra vida cotidiana; tiene las mejores posibilidades de reseñar los conflictos político-sociales de nuestro tiempo; penetra en millones de hogares del mundo entero a través del cine o la televisión (muchas veces con historias de dudosa calidad); y es notable cómo ha influenciado a casi todos los grandes escritores modernos, de todas las lenguas y de cualquier género. Pero continúa siendo considerado un género marginal. No creo que haya podido derribar esas barreras que tú señalas.

WJN: El entorno del género negro, sea una novela detectivesca o una criminal, es, casi siempre, un locus urbano con un tipo de crimen muy alejado de la violencia amanerada que se manifestaba en las casas de campo típicas de las novelas detectivescas británicas de Conan Doyle y Agatha Christie. ¿A qué se atribuye la presencia significativa de la ciudad en este género?

MG:-Es verdad que lo urbano ha jugado un rol fundamental, al menos desde que en Cosecha roja Dashiell Hammet instaló la trama en una ciudad, y además una ciudad de California. La literatura negra latinoamericana, como la europea, en general han seguido ese modelo. Pero también hay que decir que esto ha ido cambiando y se han escrito ya muchas obras cuyas tramas no se desarrollan en grandes ciudades sino en pequeñas, de provincia, y aún en el campo, o en el mar. Esto ha favorecido la ampliación del punto de vista, y ha dado lugar a estupendas novelas de acción en movimiento. Los precursores fueron el francés José Giovanni, el siciliano Giorgio Scerbananco y los norteamericanos Charles Runyon, James Cain y Charles Williams. Mis propias novelas, por cierto, como Luna caliente y El

Revista Iberoamericana, Vol. LXXVI, Núm. 231, Abril-Junio 2010, 495-503
ISSN 2154-4794 (Electrónico) 
décimo infierno, se ambientan en el Chaco y en la frontera argentino-paraguaya, y Qué solos se quedan los muertos en Zacatecas, México.

WJN: En el género negro de Latinoamérica, ¿piensa usted que el entorno urbano que se utiliza es simplemente un telón de fondo para alguna investigación detectivesca o para alguna trama criminal o adquiere una función más allá de ser el espacio en el cual la trama ocurre?

MG: -El entorno o contexto de una novela policial siempre juega un papel relevante. Y además, a mí me parece obvio que el relato negro latinoamericano se vincula casi siempre, ineludiblemente, con lo social. De manera que la ciudad, cualquiera sea su tamaño, cumple una función en la mayoría de los casos.

WJN: Uno de los temas centrales en la novela negra, y aún más en el cinenegro, es el profundo sentimiento de nostalgia y pérdida. En muchos autores latinoamericanos de género negro se nota la persistencia de esta característica. ¿Cómo se puede explicar la presencia de la nostalgia en la novela negra en Latinoamérica?

MG:-Yo diría que la explicación es muy fácil: la nostalgia en la novela negra latinoamericana se relaciona con todo lo que hemos perdido. Me parece evidente que el sentimiento de pérdida es parte de esta narrativa. Pérdida de valores, desde luego, vinculada a la pérdida de buenos niveles de vida. La pobreza absurda y chocante, la corrupción, el abuso del poder, inevitablemente remiten a tiempos en los que se vivía en paz, con mayor respeto y tranquilidad. El género negro siempre está cuestionando la pérdida de valores, porque es un género profundamente moral, y entonces el sentimiento de nostalgia deviene implícito.

WJN: No obstante, frente a este impulso nostálgico, existe una exploración de la memoria y un deseo de desenterrar un pasado reprimido. Es uno de los factores primordiales, además, que distingue la novela negra latinoamericana de las norteamericanas, protagonizadas por "hombres de acción" poco dispuestos a la contemplación del pasado. ¿Cómo se presenta y a qué se debe esta atención a la memoria en la novela negra latinoamericana?

MG: -La memoria es una misión fundamental asumida por la mayoría de los escritores latinoamericanos de nuestro tiempo. Las atrocidades cometidas por las dictaduras, el abuso constante por parte de los gobiernos norteamericanos, el resentimiento evidente en nuestros pueblos y la necesidad de restauración de una convivencia democrática, por lo menos, obligan a que toda la literatura latinoamericana esté moralmente vinculada a la necesidad de fortalecer la memoria histórica y cultural de nuestros pueblos. Véase la diferencia, por ejemplo, entre algunas novelas de Ross MacDonald, como El hombre enterrado (en las que la memoria juega un papel fundamental pero como asunto individual, y por lo tanto importante sólo a nivel psicológico personal), y cualquiera de las novelas de Osvaldo Soriano o Ramón Díaz Eterovic.

Revista Iberoamericana, Vol. LXXVI, Núm. 231, Abril-Junio 2010, 495-503
ISSN 2154-4794 (Electrónico) 
WJN: ¿Qué futuro ves para la novela negra en Latinoamérica?

MG:-En literatura, el futuro siempre depende de que se escriban buenos libros. De manera que en teoría el futuro siempre es posible, aunque a mí me parece que este género puede estar agotándose. Al menos, yo creo advertir cierta recurrencia temática, de tics, de modos narrativos, de singularidades, digamos, que no sé si son felices. Y así como la novela clásica acabó repitiéndose hasta el hartazgo, pienso que hoy el relato negro corre el mismo riesgo.

En mi opinión, el problema de la fatiga de este género es algo que merecería más atención. Y es claro que yo todavía no sé cómo se va a resolver, pero me parece que quizás ésta sea la gran limitación del género negro.

Y atención que no estoy diciendo que el género va a morir, pero yo trabajo este género desde hace más de treinta años, y para mí el problema no es la existencia o validación del género, sino la cada vez más difícil e improbable renovación. Es verdad que cada tanto el género se reactiva y algunos que se inician en él creen estar descubriendo la pólvora. Pero la verdad es que mucho, muchísimo de lo que se escribe hoy como género negro no vale nada. Aunque por suerte a cada rato aparece un buen libro, aquí o allá. Pero muchas veces me pregunto si no habremos llegado al agotamiento del género.

S) Revista Iberoamericana, Vol. LXXVI, Núm. 231, Abril-Junio 2010, 495-503 ISSN 0034-9631 (Impreso) ISSN 2154-4794 (Electrónico) 
